\title{
MATHEMATIC FINGER GAME BERPENDEKATAN OPEN-ENDED DALAM OPERASI HITUNG PENJUMLAHAN PADA SISWA SEKOLAH DASAR
}

\author{
Elly's Mersina Mursidik ${ }^{1)}$, Veni Ambarwati ${ }^{2)}$ \\ Universitas PGRI Madiun \\ ellys@unipma.ac.id \\ Universitas PGRI Madiun \\ veniambarwati018@gmail.com
}

\begin{abstract}
Abstrak
Tujuan penelitian adalah memberikan solusi alternatif dalam membantu siswa sekolah dasar untuk meningkatkan kemampuan operasi hitung penjumlahan melalui pembelajaran interaktif menggunakan mathematic finger game. Subjek penelitian adalah siswa kelas rendah sekolah dasar (kelas 1, 2 dan 3). Penelitian pengembangan dengan tahapan identifikasi tujuan, analisis kebutuhan, identifikasi tingkah laku awal siswa, merumuskan tujuan, pengembangan test acuan kriteria, pengembangan strategi pembelajaran, pengembangan dan memilih media pembelajaran, merancang. Mathematic finger game merupakan perpaduan tiga permainan jari yaitu Hompipah, suit Indonesia dan suit Jepang yang digunakan dalam menentukan pemenang, Kombinasi permainan tersebut dikaitkan dengan operasi hitung penjumlahan. Permainan dikemas menjadi pembelajaran interkatif berpendekatan open-ended dengan melibatkan kemampuan berpikir kreatif dalam menjawab permasalahan sesuai kebebasan berpikir yang terarah serta kemampuan berpikir kritis dalam memberi dan menerima masukan atas jawaban penyelesaian masalah yang dapat diterima secara logis.
\end{abstract}

Kata kunci: Mathematic finger game, Open-ended, kreatif dan kritis

\begin{abstract}
The research objective is to provide alternative solutions in helping elementary school students to improve their ability to add count operations through interactive learning using mathematical finger games. The research subjects were low grade elementary school students (grades 1,2 and 3). Development research with the stages of identifying objectives, analyzing needs, identifying students' initial behavior, formulating objectives, developing criteria reference tests, developing learning strategies, developing and selecting learning media, designing. Mathematic finger game is a combination of three finger games, namely Hompipah, Indonesian suit and Japanese suit which are used to determine the winner. The combination of these games is associated with the addition counting operation. The game is packaged into interactive learning with an open-ended approach by involving the ability to think creatively in answering problems according to directed thinking freedom and the ability to think critically in giving and receiving input on logically acceptable problem solving answers.
\end{abstract}

Keywords: Mathematic finger game, Open-ended, creative and critical

\section{Pendahuluan}

Matematika merupakan ilmu logis deduktif terstruktur, namun membelajarkan kepada siswa sekolah dasar menggunakan cara induktif. Terstrukturnya matematika dimulai dari konsep sederhana menuju konsep komplek. Kosep dasar adalah konsep pertama diterima dan dipahami oleh siswa (bilangan, operasi hitung dasar), konsep berkembang adalah konsep melatih siswa berpikir menemukan 
penyelesaian dengan cara lain dan tidak bertentangan dengan konsep dasar (komutatif, assosiatif, distributif), dan konsep ketrampilan adalah konsep usaha menyelesaikan masalah matematika berkaitan dengan aktfitas dikehidupan.

Adanya gadget memberikan dampak positif dan negatif bagi perkebangan siswa. Positifnya, siswa dapat berinteraksi antar siswa dengan jarak jauh, akan tetapi negatifnya siswa lebih sering menggunakan gadget untuk bermain game. Hal tersebut akan berdampak terhadap kemajuan belajar siswa. Sesuai permasalahan tersebut, siswa kelas rendah kesulitan melakukan proses menghitung hitung penjumlahan dan hanya menggunakan hafalan individu. Sebagian guru juga menugaskan siswa menghafal operasi hitung penjumlahan sehingga siswa terbebani dan menganggap matematika sebuah hafalan.

Kecenderungan menggunakan metode non interaktif perlu dimbangi dengan pembelajaran yang interaktif. Walaupun metode tersebut bermanfaat dan mempermudah memahami operasi hitung penjumlahan, tetapi tidak ada interkasi diskusi antar teman yang didalamnya terdapat aktifitas saling memberikan masukan / kritikan dan melatih berpikir kreatif untuk memberikan sebuah solusi. Artinya menggunakan metode belajar hanya mempermudah untuk dirinya sendiri.

Penyelesaian masalah terbuka menjadi populer dalam pendidikan matematika. Matematika setiap waktu selalu mengimplimentasikan masalah terbuka sehingga pengenalan jenis masalah matematika yang dibawa ke kelas membawa lebih dekat untuk matematika nyata (Cifarelli \& Cai, 2005 : 303). Beberapa ahli matematika telah memanfaatkan pendekatan open-ended, selain itu siswa juga mampu mengembangkan potensi memberikan solusi. Pemecahan masalah secara kreatif dan kritis tidak boleh diabaikan mulai pendidikan dasar maupun pendidikan tinggi sehingga siswa harus berkesempatan menyelesaikan masalah matematika secara kreatif, tetapi sering tidak berkesempatan (Yaftian, 2015 : 2520). Pembelajaran kolaboratif terbukti menjadi cara meningkatkan keterampilan sosial siswa, kemampuan pemecahan masalah dan kinerja pembelajaran individu (Cheng et al., 2019 : 782).

Dalam berpikir terdapat kegiatan memastikan, merancang, menghitung, mengukur, membanding, menggolong, membeda, mengkaitkan, menafsir, memprediksi, mengevaluasi analisis, sintesis, menalar, menimbang, dan, memutuskan. Berpikir berarti berupaya 
secara mental untuk memahami sesuatu yang dialami atau mencari solusi dari persoalan yang dihadapi (Mursidik et al., 2015 : 25). Kompetensi berpikir kreatif siswa masih diarahkan secara divergen tetapi menuntut aktivitas investigasi dalam pemecahan masalah matematika dari berbagai perspektif yang berbeda dengan satu tujuan yang sama. Hal ini berbeda dengan Basic skills pembelajaran matematika yang biasanya dibentuk melalui aktivitas bersifat konvergen. Pelajaran matematika SD diisyaratkan penalaran (reasoning), pemecahan masalah (problem solving) dan komunikasi (communication) adalah kompetensi yang harus dikuasai siswa. (Mursidik et al., 2015 : 23). Sederhananya, berpikir adalah proses munculnya gagasan secara internal dalam pikiran yang melibatkan beberapa manipulasi pengetahuan dalam sistem kognitif dan dapat diamati, diarahkan serta menghasilkan perilaku memunculkan solusi.

Pembahasan penelitian ini tentang kebermanfaatan pembelajaran interaktif mathematic finger game berpendekatan open-ended terhadap kemampuan hitung penjumlahan. Kolaborasi permaian yang familier membantu siswa memahami operasi hitung penjumlahan yang diperlukan secara kelompok, terutama untuk mengatasi kesulitan belajar siswa.

\section{Permainan Jari (finger game)}

Kinerja matematika anak-anak selama pertandingan permainan dapat menunjukkan semangat belajar dan memenangkannya (Vandermaas-Peeler et al., 2012 : 1305). Dukungan persepsi dan bimbingan orang tua terhadap kinerja berhitung anak-anak setelah bermain game bersama-sama. Kegembiraan anak-anak tentang operasi hitung angka dapat dengan mudah dimasukkan dalam konteks kegiatan sehari-hari. Sehingga orang tua hanya menerima laporan setiap perubahan kemampuan berhitung setelah bermain bersama.

Masalah dan tujuan belajar dibangun oleh anak-anak terkait dengan kemampuan pemahaman yang berbeda untuk mencapainya secara bersamasama, sehingga perlu mengatur agar anak-anak bermain dalam konfigurasi kemampuan yang serupa dan campuran (Guberman \& Saxe, 2000 : 202). Dengan kemampuan awal siswa yang berbeda dalam belajar berhitung memberikan dinamika yang menarik saat permainan sehingga siswa yang memeliki kemampuan tinggi akan memberikan jawaban yang benar dengan cepat dibandingakan dengan siswa dengan

63 | Mathematic Finger Game Berpendekatan Open-Ended dalam Operasi Hitung..... 
kemampuan sedang maupun rendah

Aturan permainan memberikan keteraturan yang digunakan mengambil bentuk dalam bermain anak-anak dan membagai peran pemain sehingga permainan dapat dimainkan sesuai tujuan belajar (Guberman \& Saxe, 2000 :214). Hal ini bertujuan untuk menentukan siapa yang melakukan aktifitas pertama dan dilanjutkan aktifitas berikutnya dengan anak yang sama atau berbeda.

\section{Pendekatan Open-ended}

Pembelajaran

harus mengutamakan proses dengan menggunakan jawaban yang benar atas masalah yang diberikan untuk memberikan pengalaman di dalam menemukan sesuatu yang baru dalam proses tersebut. Proses ini bisa dilakukan melalui kombinasi pengetahuan yang dimiliki siswa, ketrampilan atau cara berfikir yang sudah dipelajari oleh siswa sebelumnya. Pembelajaran dengan pendekatan openended adalah suatu permasalahan terbuka yang diberikan kepada siswa dengan pengetahuan, cara, dan metode yang berbeda dalam menjawab permasalahan yang diberikan (Mursidik et al., 2015 : 28). Kemajuan konseptual pemecahan masalah terbuka berkelanjutan membentuk dan meformulasikan ulang dalam rangka untuk mengembangkan solusi. Kebebasan intelektual dalam masalah terbuka yang dialami merupakan solusi sementara melihat langsung memecahkan masalah yang diarahkan untuk melihat dan mempertimbangkan ide-ide baru serta pendekatan yang dapat menyebabkan solusi (Cifarelli \& Cai, 2005 : 303). Pendekatan Openended merupakan suatu pendekatan untuk pemecahan masalah yang diyakini dapat mendorong kreativitas dan inovasi berpikir matematika siswa secara lebih bervariasi (Rudyanto et al., $2019: 2$ ).

Pendekatan open-ended dapat mendorong siswa untuk berpikir lebih kritis, tebuka, mampu bekerja sama, dan berkompeten dalam pemecahan masalah dan berkomunikasi secara logis dan argumentatif. Pendekatan openended dilakukan dengan penyajian masalah dengan jawaban benar lebih dari satu atau banyak cara mendapatkan jawaban benar, sehingga siswa secara bebas menggunakan kemampuan, ideide, dan skill matematikanya. Selain itu, pendekatan pemecahan masalah openended mampu untuk bernalar dan mengkomunikasikan ide-idenya dalam memberikan klarifikasi dan alasanalasan terkait dengan jawabannya. 
Matematika di Sekolah Dasar

Matematika merupakan disiplin ilmu universal yang terus berkembang serta ilmu dasar diberbagai disiplin ilmu untuk memajukan daya pikir manusia di kehidupan. Belajar matematika di sekolah diperlukan penguasaan dasar kemampuan berpikir secara sistematis, kritis, analitis, logis, dan kreatif serta menumbuhkan kemampuan bekerja sama terhadap dinamika kehidupan yang kompetitif. BSNP (2007: 11) menjelaskan bahwa tujuan pelajaran matematika yaitu (1) memahami konsep dan menjelaskan keterkaitan antar konsep dan mengaplikasikan konsep atau algoritma, secara luwes, akurat, efisien, dan tepat, dalam pemecahan masalah; menggunakan penalaran pola dan sifat, melakukan manipulasi dalam membuat generalisasi, menyusun bukti pernyataan matematika; (3) kemampuan memahami memecahkan masalah, merancang dan menyelesaikan model serta menafsirkan solusi; (4) mengomunikasikan gagasan dengan simbol, tabel, diagram, atau media lain untuk memperjelas keadaan atau masalah; (5) Memiliki sikap menghargai kegunaan matematika dalam kehidupan dengan memiliki rasa ingin tahu, perhatian, dan minat mempelajari matematika, serta sikap ulet dan percaya diri dalam pemecahan masalah.

Kemendikbud dalam Wandini dan Banurea, (2019 : 12) menjelaskan tujuan umum matematika fokus pada penataan nalar dan pembentukan sikap serta keterampilan penerapan matematika. Tujuan khusus matematika SD yaitu: (1) menumbuhkan dan mengembangkan ketrampilan berhitung dalam kehidupan, (2) menumbuhkan kemampuan siswa yang dapat dialihgunakan melalui kegiatan matematika,

mengembangkan kemampuan dasar matematika sebagai bekal belajar selanjutnya, (4) membentuk sikap logis, kritis, cermat, kreatif dan disiplin

Numerasi yaitu bukan kemampuan menghitung saja, tetapi kemampuan mengaplikasikan konsep berhitung yang abstrak atau nyata, karena merupakan dua area fundamental penting pada semua mata pelajaran yang hanya bisa mencapai pembelajaran nyata jika bisa memahami logikanya literasi dan numerasi (Putranto \& Daniswar, 2019). Literasi numerasi merupakan bagian dari matematika. Komponen literasi numerasi diambil dari cakupan matematika di dalam Kurikulum 2013, seperti terlihat dalam tabel 1. 
Tabel 1. Komponen Literasi Numerasi dalam Cakupan Matematika Kurikulum 2013

\begin{tabular}{|l|l|}
\hline \multicolumn{1}{|c|}{ Komponen Literasi Numerasi } & $\begin{array}{l}\text { Matematika } \\
\text { Kurikulum 2013 }\end{array}$ \\
\hline $\begin{array}{l}\text { Mengestimasi dan menghitung } \\
\text { dengan bilangan bulat }\end{array}$ & Bilangan \\
\hline $\begin{array}{l}\text { Menggunakan pecahan, desimal, } \\
\text { persen, dan perbandingan }\end{array}$ & Bilangan \\
\hline $\begin{array}{l}\text { Mengenali dan menggunakan pola } \\
\text { dan relasi }\end{array}$ & $\begin{array}{l}\text { Bilangan dan } \\
\text { Aljabar }\end{array}$ \\
\hline Menggunakan penalaran spasial & $\begin{array}{l}\text { Geometri dan } \\
\text { Pengukuran }\end{array}$ \\
\hline Menggunakan pengukuran & $\begin{array}{l}\text { Geometri dan } \\
\text { Pengukuran }\end{array}$ \\
\hline Menginterpretasi informasi statistik & $\begin{array}{l}\text { Pengolahan } \\
\text { Data }\end{array}$ \\
\hline
\end{tabular}

(Han et al., $2017: 6$ )

Literasi matematis adalah siswa yang dapat dilaksanakan di kemampuan memahami dan lingkungan keluarga, sekolah dan mengaplikasikan matematika dalam masyarakat.

pemecahan masalah kehidupan seharihari untuk segala usia melalui aktivitas pengajuan masalah (problem posing), pemecahan masalah (problem solving), dan investigasi matematis dengan pembelajaran berbasis pemecahan masalah (problem solving), pembelajaran nyata (realistic mathematics education) atau kontekstual (contextual teaching-learning), serta menggunakan pendekatan open-ended (open-ended approach). (Abdussakir, $2018: 15)$

Ilustrasi pembelajaran matematika di sekolah dasar diusahakan secara konkrit dan kontekstual dengan pendekatan open-ended sehingga dapat menjadikan pembelajaran interaktif antar

\section{Subjek dan Metode Penelitian}

Subjek penelitian adalah siswa kelas rendah sekolah dasar (kelas 1, 2 dan 3). Penelitian pengembangan dengan tahapan (1) Identifikasi tujuan pembelajaran dengan menentukan harapan siswa untuk meningkatkan kemampuan operasi hitung penjumlahan; (2) Analisis kebutuhan dengan mengidentifikasi kebutuhan siswa untuk mempermudah belajar operasi hitung penjumlahan; Identifikasi tingkah laku siswa kelas rendah terhadap aktifitas di dalam dan di luar kelas; (4) Merumuskan tujuan pembelajaran berdasarkan analisis kebutuhan dan tingkah laku siswa; (5) Mengembangkan tes acuan kriteria

66 | Autentik: Jurnal Pengembangan Pendidikan Dasar, Vol.5, No.1, Februari 2021 
dengan membuat panduan permainan mathematic finger game;

Pengembangan strategi pembelajaran sesuai analisis kebutuhan dan identifikasi tingkah laku untuk melaksanakan pembelajaran dengan cara lain; (7) Mengembangkan dan memilih media pembelajaran yang disesuaikan dengan strategi pembelajaran; (8) Merancang dan melaksanakan evaluasi untuk memperoleh informasi peningkatan kemampuan hitung penjumlahan.

\section{Hasil dan Pembahasan}

Hasil penelitian pada dasarnya merupakan jawaban atas masalah yang telah dirumuskan yaitu kebermanfaatan pembelajaran interaktif dengan menggunakan mathematic finger game terhadap hasil belajar matematika pada operasi hitung dasar penjumlahan. Adapun hasil penelitian sebagai berikut:

1) Hasil identifikasi tujuan pembelajaran diperoleh informasi bahwa harapan capaian belajar matematika dalam menguasai kemampuan operasi hitung penjumlahan mendukung pemahaman siswa terhadap kompetesi numerasi yang harus dikuasai oleh siswa sekolah dasar.

2) Analisis instruksional pembelajaran diperoleh hasil bahwa siswa sekolah dasar dalam pembelajaran matematika ditutut untuk mampu mengerti, memahami dan melakukan operasi hitung penjumlahan untuk proses memudahkan pemahaman materi matematika yang berkaitan dengan operasi hitung bahkan harus diaplikasikan di kehidupan nyata.

3) Identifikasi tingkah laku dan karakteristik awal ditemukan bahwa siswa sekolah dasar belajar menguasai operasi hitung dasar penjumlahan dengan menggunakan berbagai metode secara mandiri dengan mengingat / menghafal akan tetapi belum dapat terjadi pembalajarann yang interaktif dengan temannya. Hal ini dilakukan karena tututan pecapaian kopetensi kemampuan hitung dasar terutama pada operasi penjumlahan.

4) Berdasarkan hasil analisis instruksional dan informasi tingkah laku awal, dapat dirumuskan bahwa untuk meningkatakan kemampuan operasi hitung penjumlahan dan perkalian diperlukan sebuah cara interaktif dalam belajar. Pembelajaran interaktif dengan cara memadukan permainan hompipah, suit Indonesia (gajah, orang, semut) dan suit Jepang (gunting, batu, kertas) yang dimodifikasi untuk permainan matematika. Permainan tersebut diharapkan dapat membantu siswa untuk belajar operasi hitung dasar penjumlahan secara interaktif; 
5) Tes acuan patokan dirancang dalam bentuk panduan permainan mathematic finger game. Permainan tersebut sudah terdapat tes yang dapat mengukur kemampuan hitung penjumlahan yang harus dicapai oleh siswa (tabel. 2). Pada permainan ini siswa akan berinterakasi dan berkompetisi untuk menjadi pemenang sehingga pemenang memiliki kemampuan hitung tinggi dibanding yang kalah, sedangkan siswa yang kalah akan merefleksi diri kelemahannya dan kemudian berusaha meningkatkan kemampuannya agar menjadi pemenang.

Tabel. 2. Acuan bilangan dalam permainan mathematic finger game pada operasi penjumlahan

\begin{tabular}{|c|c|l|}
\hline Kelas & Bilangan & Banyak Pemain \\
\hline 1 & Asli & 2 siswa \\
\hline \multirow{2}{*}{2} & Asli & 2 siswa lebih \\
\cline { 2 - 3 } & Cacah & 2 siswa \\
\hline \multirow{2}{*}{3} & Cacah & 2 siswa lebih \\
\cline { 2 - 3 } & Bulat & 2 siswa \\
\hline
\end{tabular}

6) Mengembangkan strategi atau pun jam kosong. Sehingga siswa pembelajaran. Strategi pembelajaran dapat memanfaatkan waktu di luar jam dengan permainan mathematic finger pelajaran untuk belajar operasi hitung. game didasarkan kebutuhan dan Permainan ini diujicobakan pada siswa tuntutan siswa untuk menguasi operasi sekolah dasar di luar lingkungan sekolah hitung penjumlahan. Strategi ini dan hasilnya siswa dapat mempraktikan disesuaikan dengan kebiasaan siswa serta menarik perhatian siswa untuk sekolah dasar yang masih suka bermain terus mencoba menjadi pemenang. dengan temannya di luar jam pelajaran

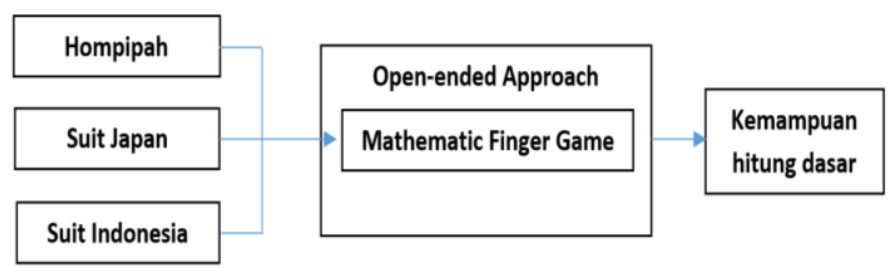

Gambar.1. Kerangka pengembangan

7) Mengembangkan dan memilih bahan- operasi hitung yang dapat dimainkan bahan pembelajaran yang sesuai. dalam pemainan ini disesuaikan level Mengembangkan materi bilangan dan kemampuan siswa. Materi bilangan dan 
operasi hitung pada permainan ini dikelompokan sesuai dengan kopetensi yang harus dikuasi siswa berdasarkan jenjang kelasnya. Dalam permainan ini menggunakan simbol angka dari bahasa isyarat dan merupakan media komunikasi untuk membuat otak lebih aktif serta serta membantu interaksi, kematangan sosial, dan perkembangan kognitif. Bahasa merupakan kemampuan manusia yang digunakan untuk berkomunikasi dengan manusia lain dengan tanda ataupun gerakan (Basuki, et. al, 2016; Krisnan, 2017)

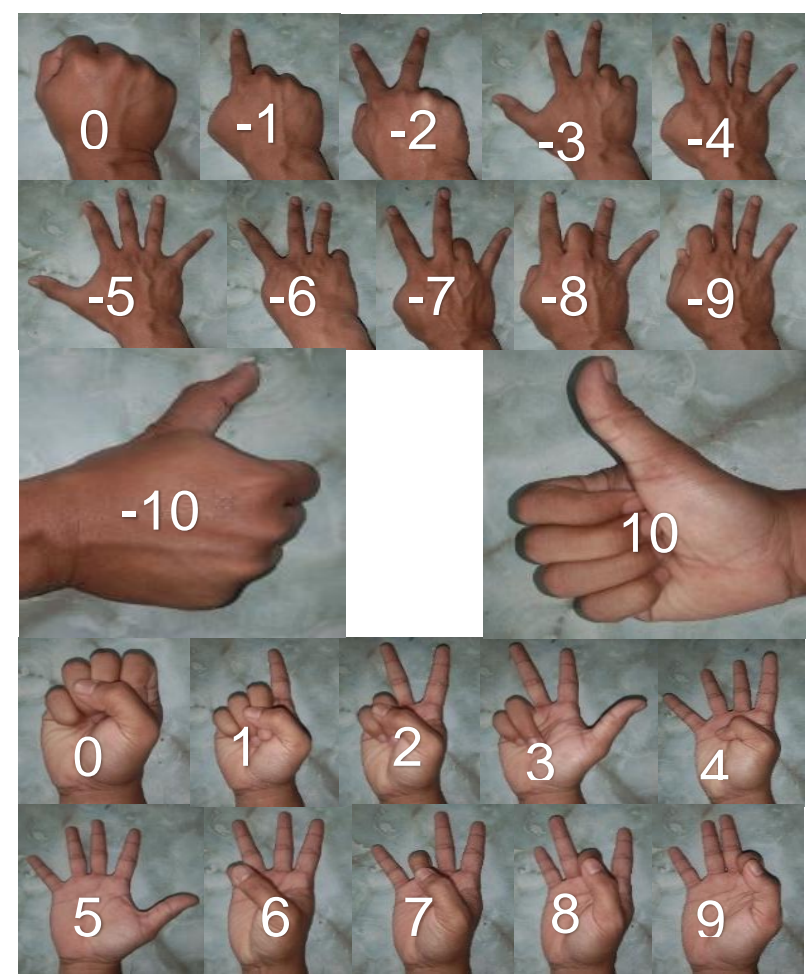

Gambar. 2. Simbol angka menggunakan jari

\section{Mathematic finger game}

Mathematic finger

belakang pada telapak tangan untuk merukapan perpaduan tiga permaian Indonesia atau Japan adalah permainan tradisional yang sudah familier yaitu tangan yang dimainkan oleh dua orang "Hompipah, Suit Indonesia dan Suit ala untuk menentukan pemenang dengan Japan". Pada permainan tersebut menggunakan jari. Permainan ini dapat diharuskan ada interaksi dengan individu dimainkan oleh semua kalangan umur langsung minimal dua siswa. Hompipah dari anak-anak sampai orang dewasa. adalah pemainan tangan yang Permainan ini di Indonesia hanya terdiri menggunakan sisi depan dan sisi tiga pilihan yaitu gajah (ibujari), manusia 
(telunjuk) dan semut (jari kelingking), sedangkan permainan jari dari Jepang terdiri dari gunting (jari telunjuk dan jari tengan), batu (semua jari mengepal) dan kertas (semua jari membuka).

Modifikasi permainan jari yang dapat difungsikan sebagai kegiatan belajar perlu diperbaiki dan diperbarui aturannya jika digunakan dalam kegiatan belajar matematika. Permainan dapat menjadi sebuah kegiatan interaktif antar siswa yang saling memberi dan menerima kritikan. Permainan ini diharapkan mampu membentuk sikap saling menghargai pendapat orang lain serta melatih kemapuan berpikir kreatif siswa dalam menjawab pertanyaan secara langsung menggunakan caranya sendiri.

Prinsip dasar permainan sesuai dengan sistem matematika yaitu: (1) adanya himpunan bilangan yang dibicarakan; (2) operasi hitung yang dikerjakan dan (3) jawaban hasil yang harus dicari. Adapun aturan dalam permainan ini yaitu: (1) Permainan mengunakan simbol angka dari 5 jari (ibu jari, telunjuk, jari tengan, jari manis dan jari kelingking); (2) Pemain tidak terbatas hanya 2 pemain tetapi bisa dimainkan lebih dari 2 atau secara berkelompok; (3) Pemainan dikaitkan dengan operasi hitung penjumlahan; (4) Menang atau kalah di permainan ini ditentukan oleh jumlah jawaban benar pada operasi hitung matematika yang dijawab oleh pemain. Walaupun pemain dapat menjawab pada pertama kali tetapi jawabannya salah maka pemain terebut kalah dan dilanjutkan oleh pemain berikutnya untuk sampai menjawab dengan benar.

\section{Kesimpulan}

Hasil pengembangan mathematic finger game dengan kombinasi tiga permainan jari yang berbeda memberikan manfaat positif terhadap ketertarikan siswa untuk terus mencoba menjadi pemenang sehingga permainan ini dapat digunakan sebagai media belajar siswa meningkatkan kemampuan hitung penjumlah. Permainan ini dapat disesuaikan dengan kompetensi pada kelas rendah tentang bilangan asli dan cacah, namun pada bilangan bulat digunakan sebagai tahap pengenalan awal. Perlu diperhatikan bahwa belajar operasi hitung penjumlahan tidak hanya dilakukan di dalam kelas saat jam pelajaran akan tetapi dapat dilakukan dengan cara yang menyenangkan yang dapat dilakaukan dimanapun tempatnya dan kapanpun waktunya. 


\section{Daftar Pustaka}

Abdussakir. (2018). Literasi Matematis dan Upaya Pengembangannya dalam Pembelajaran di Kelas. Seminar Pendidikan Matematika, 1-16.

Basuki, A., Zikky, M., Hasim, J. A. N., \& Ramadhan, N. I., 2016. Sensor Gerak Dengan Leap Motion untuk Membantu Komunikasi Tuna Rungu/Wicara. https://www.researchgate.net/figure/Gambar-3-Data-gerakan-tanganuntuk-angka fig1 320472422. Diakses 28 Juli 2020

BSNP. 2007. Kurikulum Tingkat Satuan Pendidikan Sekolah Dasar. Jakarta: Depdiknas

Cheng, Y. W., Wang, Y., Cheng, I. L., \& Chen, N. S. (2019). An in-depth analysis of the interaction transitions in a collaborative Augmented Reality-based mathematic game. Interactive Learning Environments, 27(5-6), 782-796. https://doi.org/10.1080/10494820.2019.1610448

Cifarelli, V. V., \& Cai, J. (2005). The evolution of mathematical explorations in open-ended problem-solving situations. Journal of Mathematical Behavior, 24(3-4), 302-324. https://doi.org/10.1016/j.jmathb.2005.09.007

Putranto, W.G., Daniswara, W., 2019, "Nadiem Makarim Jelaskan Literasi dan Numerasi, 2 Aspek Asesmen Kompetensi Pengganti Ujian“" https://www.tribunnews.com/nasional/2019/12/16/nadiem-makarimjelaskan-literasi-dan-numerasi-2-aspek-asesmen-kompetensi-penggantiujian-nasional. Diakses 25 Februari 2020

Guberman, S. R., \& Saxe, G. B. (2000). Mathematical Problems and Goals in Children's Play of an Educational Game. Mind, Culture and Activity, 7(3), 217-226. https://doi.org/10.1207/S15327884MCA0703

Han, W., Susanto, D., Dewayani, S., Pandora, P., Hanifah, N., Miftahussururi, Nenti, M. N., \& Akbari, Q. S. (2017). Materi Pendukung Literasi Numerasi. Kementerian Pendidikan Dan Kebudayaan, 9, 1689-1699. https://doi.org/10.1017/CBO9781107415324.004

Mursidik, E. M., Samsiyah, N., \& Rudyanto, H. E. (2015). Kemampuan Berpikir Kreatif Dalam Memecahkan Masalah Matetatika Open-Ended Ditinjau Dari Tingkat Kemampuan Matematika Siswa Sekolah Dasar. PEDAGOGIA: Jurnal Pendidikan, 4(1), 23. https://doi.org/10.21070/pedagogia.v4i1.69

Krisnan. 2017. Belajar Bahasa Isyarat Tingkat Dasar: Mengenal Huruf dan Angka, https://meenta.net/belajar-bahasa-isyarat-dasar/. Diakses 27 Juli 2020

Rudyanto, H. E., Hadi, F. R., \& Winanto, A. (2019). Singapore Bar Model Approach in Teaching Math VI Open Ended Mathematical Problem Solving: an Analysis of Elementary Students ' Creative Thinking Abilities. Journal of Physics: Conference Series. https://doi.org/10.1088/17426596/1254/1/012078

Vandermaas-Peeler, M., Ferretti, L., \& Loving, S. (2012). Playing The Ladybug Game: Parent guidance of young children's numeracy activities. Early Child Development and Care, 182(10), 1289-1307. https://doi.org/10.1080/03004430.2011.609617

Wandini, R.R., \& Banurea, O.K., 2019, Pembelajaran Matematika Untuk Calon

71 | Mathematic Finger Game Berpendekatan Open-Ended dalam Operasi Hitung..... 
Elly's Mersina Mursidik, Veni Ambarwati

Guru MI/SD, Edisi I, Medan, CV. Widya Puspita.

Yaftian, N. (2015). The Outlook of the Mathematicians' Creative Processes. Procedia - Social and Behavioral Sciences, 191, 2519-2525. https://doi.org/10.1016/j.sbspro.2015.04.617 